\title{
VARIABEL ANTESEDEN INTENTION TO STAY PEKERJA MILENIAL DENGAN KERJA REMOTE DI JAKARTA SEKITARNYA
}

\author{
ANTECEDENT VARIABLES OF INTENTION TO STAY FOR MILLENNIAL WORKERS WITH \\ REMOTE WORK IN SURROUNDING JAKARTA
}

\author{
Kevin Kristiawan Elison*), Sylvia Diana Purba ${ }^{*}{ }^{* 1}$ \\ ${ }^{*}$ Program Studi Manajemen, Fakultas Ekonomi dan Bisnis, Universitas Katolik Indonesia Atma Jaya \\ J1. Jenderal Sudirman 51, Jakarta 12930, Indonesia
}

\begin{abstract}
The millennial generation that dominates the workforce today has dynamic characteristics and high turnover intention. Job design that is autonomous and passion is considered to make millennial more sustainable in one company. This study was conducted to examine the antecedent effect of the intention to stay variable, namely task characteristics autonomy, passion, and job satisfaction with the intention to stay with 100 millennial remote workers in Jakarta as respondents. Data obtained from questionnaires distributed via g-form with purposive sampling method and convenience sampling technique. Data processing using SMART PLS 3.0 software with Bootstrapping analysis method. The results of this study prove that job satisfaction can increase intention to stay and is able to mediate the effect of passion and task characteristics autonomy on intention to stay. The results also prove that passion can significantly increase job satisfaction and intention to stay. Likewise, job characteristic autonomy has a significant effect on job satisfaction. Passion, job characteristic autonomy, job satisfaction are antecedents of variables that determine the intention to stay for millennial workers with remote work.
\end{abstract}

Keywords: intention to stay, job satisfaction, task characteristic autonomy, passion, remote workers

\begin{abstract}
Abstrak: Generasi milenial yang mendominasi angkatan kerja saat ini memiliki karakteristik yang dinamis dan turnover intention yang tinggi. Desain pekerjaan yang otonomi dan passion dianggap dapat membuat milenial lebih bertahan dalam satu perusahaan. Penelitian ini dilakukan untuk menguji efek anteseden variabel intention to stay, yaitu task characteristics autonomy, passion dan job satisfaction terhadap intention to stay dengan 100 remote workers milenial di Jakarta sebagai responden. Data diperoleh dari kuesioner yang disebar melalui g-form dengan metode purposive sampling. Pengolahan data menggunakan software SMART PLS 3.0 dengan metode analisis Bootstrapping. Hasil penelitian ini membuktikan bahwa job satisfaction dapat meningkatkan intention to stay dan mampu memediasi pengaruh passion dan task characteristics autonomy terhadap intention to stay. Hasil juga membuktikan passion dapat meningkatkan job satisfaction dan intention to stay secara signifikan. Demikian pula job characteristic autonomy signifikan berpengaruh terhadap job satisfaction. Passion, job characteristic autonomy, job satisfaction menjadi anteseden variabel yang menentukan intention to stay pada pekerja milenial dengan kerja remote.
\end{abstract}

Kata kunci: niat untuk tinggal, kepuasan kerja, otonomi tugas, pasion, bekerja jarak jauh

\footnotetext{
${ }^{1}$ Alamat Korespondensi:

Email: sylvia.purba@atmajaya.ac.id
} 


\section{PENDAHULUAN}

Dalam angkatan kerja saat ini, generasi milenial diekspektasikan akan memenuhi 75 persen tenaga kerja global dalam satu dekade kedepan. Di Indonesia sendiri generasi milenial semakin berkembang jumlahnya bahkan telah menyentuh 105 juta orang (Bappenas, 2018 dalam Tulung et al. 2019). Generasi millenial yang lahir pada tahun 1980-2001 (Zemke et al. 2000) memiliki ciri lebih ambisius dan kompetitif menyukai pekerjaan berprofil tinggi selama tahap awal karir. Millennials akan mencari pekerjaan yang penuh arti serta mendukung autonomy, kebebasan, dan memiliki kecenderungan untuk meninggalkan organisasi yang mendukung birokrasi manajemen tradisional (Armour, 2005; Becton et al. 2014). Oleh karena itu, banyak millennials kemudian memilih resign dari perusahaan yangmemilikicarakerja konvensionaldan lebihmemilih untuk bekerja di perusahaan yang mengakomodasi fleksibilitas serta tantangan untuk berkembang. Dewasa ini, di Indonesia tampak tren perusahaan yang mengimplementasikan remote working semakin banyak. Pekerjaan yang tadinya hanya dapat dilakukan dari kantor, sekarang dapat dilakukan dari mana saja tak terkecuali dari rumah. Millennials di Indonesia akan segera memenuhi angkatan kerja yang ada. Namun sayangnya, generasi milenial memiliki tingkat turnover yang tinggi (Frian dan Mulyani, 2018). Jika perusahaan tidak dapat memberikan kesempatan bagi millennials untuk sepenuhnya membangun keahlian mereka, ketidakpuasan tingkat tinggi akan terjadi. Hasilnya, gagasan bahwa karir seumur hidupnya akan dihabiskan dengan satu perusahaan kemungkinan tidak terjadi (Delcampo et al. 2011).

Turnover adalah peristiwa yang tidak diinginkan dalam organisasi karena kehilangan karyawan yang kurang dikelola dengan baik dapat mengganggu komunitas organisasi yang ada dan mengurangi moral bagi mereka yang tetap tinggal (Allen et al. 2010). Oleh karena itu, perlu diketahui variabel yang mampu meningkatkan Intention to Stay. Salah satu faktor yang dianggap dapat meningkatkan kepuasan kerja agar karyawan mau bertahan adalah job design yang sesuai. Job Design secara khusus diakui sebagai bagian dari lingkungan kerja yang penting sebagai antisipasi terhadap Turnover Intention (Hackman dan Oldham, 1975; Holtom et al. 2008). Hackman dan Oldham (1975) mengemukakan tentang pekerjaan yang dirancang dengan memuat informasi tentang pekerjaan yang menentukan potensi pekerjaan, yaitu, Identitas Tugas, Otonomi, Umpan
Balik Pekerjaan, Variasi Tugas dan Signifikansi Tugas. Pekerjaan yang memberikan otonomi dan variasi kepada karyawan dapat memperkuat perasaan karyawan melalui tingkat kompetensi dan kebebasan menentukan nasib sendiri. Dimensi JCM yang menyatakan otonomi dalam bekerja disebut sebagai task characteristic autonomy (TCA).TCA adalah sebuah konsep yang menyarankan bahwa tingkat autonomy dalam pekerjaan tercermin dari sejauh mana suatu pekerjaan memberikan kebebasan, kemandirian, dan kebijaksanaan untuk menjadwalkan pekerjaan itu sendiri, membuat keputusan, dan memilih metode yang digunakan untuk melakukan tugas (Breaugh, 1985; Wall et al. 1992; Wall et al. 1995).

Penelitian ini berbeda dengan penelitian sebelumnya yang menguji turnover millenial dengan kerja konvensional, (Frian dan Mulyani, 2018) dalam penelitian ini milenial yang menjadi responden adalah milenial yang dengan kerja remote yang dianggap sesuai dengan profil milenial. Penelitian ini sangat relevan dengan kondisi pandemi yang telah banyak mempercepat perubahan dunia kerja ke dunia kerja virtual.

Dengan penelitian ini akan diuji apakah sistem kerja remote dan otonomi dapat membuat millenial lebih bertahan di perusahaan. Oleh karena itu penelitian ini bertujuan menguji apakah passion dapat meningkatkan kepuasan kerja dan juga niat untuk tinggal. Penelitian juga akan menguji apakah otonomi tugas dapat meningkatkan kepuasan kerja dan juga keinginan untuk tinggal. Selanjutnya juga menguji apakah kepuasan kerja dapat meningkatkan keinginan untuk tinggal dan sekaligus memediasi pengaruh pasion dan otonomi tugas terhadap niat untuk tinggal.

\section{METODE PENELITIAN}

Penelitian ini dilakukan di Jakarta pada semesterpertama tahun 2020. Jenis data yang digunakan dalam penelitian ini merupakan data primer. Pengambilan data penelitian dilakukan melalui penyebaran kuesioner secara online melalui google form sejak bulan Mei sampai dengan Juni 2020. Sample diambil dengan metode purpossive dengan jumlah sampel 100 orang karyawan remote workers dengan kriteria yang ditentukan telah bekerja minimal dua tahun di perusahaan tersebut serta lahir antara tahun 1980-1995 dengan jenis pekerjaan yang lebih otonom atau bisa dikerjakan dari jarak jauh 
(Remote Working). Jumlah ini diperoleh setelah memilih 100 responden yang memenuhi kriteria dari 210 orang yang merespon g-form dalam kurun waktu dua bulan di mana 110 diantaranya ada yang bukan milenial dan bekerja kurang dari 2 tahun. Metode sampling menggunakan teknik convinience sampling, karena metode ini dianggap paling sesuai dengan karakteristik responden yang dibutuhkan mengingat keterbatasan waktu dan biaya. Jenis pertanyaan yang ada di dalam kuesioner penelitian ini merupakan scaled response questions. Skala yang digunakan untuk mengukur seluruh indikator adalah 5 skala likert.

Penelitian ini menggunakan analisis kuantitatif dengan pendekatan SEM (Structural Equation Modeling) PLS (Partial Least Square) menggunakan software SMART PLS 3.0. Teknik pengolahan data dan analisis data menggunakan Overall Mean Score analysis, uji validitas dan reliabilitas, serta pengujian hipotesis menggunakan bootstrapping. Indikator yang digunakan pada variabel Passion adalah Harmonious Passion, Obsessive Passion, dan general passion kuesioner yang digunakan berdasarkan Vallerand (2003) yang telah dimodifikasi. Indikator variabel Task Characteristics Autonomy adalah work scheduling autonomy, decision-making autonomy, work method autonomy menggunakan workdesign questionnaire Morgeson dan Humprey (2006) yang telah dimodifikasi. Indikator job satisfaction adalah work it-self, reward, relation, job in general, growth kuesioner berdasarkan Spector (1997) yang telah dimodifikasi. Indikator variabel intention to stay adalah pikiran untuk bertahan, mencari alternatif, dan niat untuk bertahan menggunakan kuesioner Mobley et al. (1978) turnover intention reversed yang telah dimodifikasi. (Jumlah dan item kuesioner dapat dilihat pada uji validity)

Pada dasarnya, job design para remote worker berbeda dengan job design karyawan konvensional. Hal tersebut dapat dilihat dari berbedanya lokasi tempat pekerjaan, cara bekerja, dan sistem controlling. Hal ini khususnya berkaitan dengan tingkat kebebasan yang diberikan dalam bekerja atau Task Characteristics Autonomy, sehingga dalam penelitian ini peneliti berharap dapat menemukan sejauh mana job design remote workers khususnya task characteristics autonomy dapat memengaruhi Intention to Stay para karyawannya. Mustapha, dkk. (2010) mengatakan bahwa job design dalam job autonomy berpengaruh positif signifikan terhadap intention to stay.
Selain dari job design yang berbeda pekerjaan remote membutuhkan tingkat passion yang cukup agar menjaga seseorang tetap bekerja dengan baik. Passion sendiri menjadi variabel yang cukup penting dalam pengambilan keputusan kerja. Houlfort et al. (2014) berpendapat bahwa Harmonious passion secara positif memengaruhi work satisfaction dan menurunkan tingkat depresi serta menurunkan tingkat turnover intention. Peneliti menduga seiring meningkatnya passion seseorang, maka akan diikuti dengan tingkat intention to stay yang meningkat. Dengan meningkatnya passion serta job design yang baik, diharapkan akan meningkatkan job satisfaction para remote workers. Diketahui Passion memiliki kaitan signifikan dengan job satisfaction (Burke et al. 2015).

Job satisfaction merupakan variabel yang mampu memengaruhi secara langsung turnover intention seorang karyawan (Purba dan Ananta, 2018). Cho et al. (2012) berpendapat bahwa untuk dapat mengurangi Turnover, organisasi dapat menerapkan strategi untuk meningkatkan Job Satisfaction. Dengan kata lain menurunkan turnover intention akan meningkatkan intention to stay. Job satisfaction merupakan variabel yang mampu memengaruhi secara langsung komitmen kerja seorang karyawan (Oktariani et al. 2017). Agarwal dan Gupta (2018) mengemukakan bahwa Job Characteristics berpengaruh signifikan negatif terhadap Turnover intention para manajer. Selanjutnya, Abid et al. (2013) menyatakan terdapat korelasi positif yang signifikan antara job design terhadap tingkat satisfaction pekerja dan berlaku sebaliknya. Hal ini sejalan dengan temuan Ferreira et al. (2017) yang menyatakan bahwa Job satisfaction mampu memediasi hubungan antara task characteristics (significance dan identity) terhadap turnover intention karyawan, yang mana sebaliknya dapat meningkatkan intention to stay. Temuan dari penelitian terdahulu semakin memperkuat dugaan penulis dalam penelitian ini bahwa job satisfaction mampu memediasi pengaruh passion dan job design terhadap intention to stay remote workers millennials di Jakarta. Berikut kerangka pemikiran seperti terlihat dalam Gambar 1.

Berdasarkan uraian sebelumnya, peneliti mengajukan hipotesis sebagai berikut :

H1: Passion berpengaruh signifikan terhadap Intention to Stay Remote Workers

H2: Job Design (Task Characteristics Autonomy) berpengaruh signifikan terhadap Intention to Stay Remote Workers 
H3: Passion berpengaruh signifikan terhadap Job Satisfaction Remote Workers

H4: Job Design (Task Characteristics Autonomy) berpengaruh terhadap Job Satisfaction Remote Workers

H5: Variable Job Satisfaction mampu memediasi pengaruh variable Job Design (Task characteristics Autonomy) dan Passion terhadap Intention to Stay Remote Workers.

\section{HASIL}

\section{Gambaran Umum Objek Penelitian}

Pemerintah Amerika Serikat mendefinisikan Telecommuting atau Remote Workers sebagai kemampuan untuk melakukan pekerjaan di lokasi selain dari kantor resmi, yang dilakukan secara rutin, teratur, dan dilakukan lebih dari satu hari dalam sepekan (Woog dalam Olorunfemi, 2013). Pada penelitian ini, setiap pekerja yang mampu bekerja secara rutin dan teratur dan dilakukan lebih dari satu hari dalam sepekan dianggap sebagai Remote Workers. Pada penelitian ini responden adalah yang memenuhi kriteria bekerja di Jakarta sekitarnya, dan telah bekerja lebih dari 2 tahun, lahir antara 1980-1995 serta sering bekerja secara jarak jauh (bekerja remote). Penelitian ini membutuhkan kategori subjek tertentu yang dapat digunakan sebagai sampel dengan syarat: 1) Dapat bekerja secara remote;2) Telah bekerja di perusahaan sekarang lebih dari 2 tahun; 3) Gen Millenial; 4) Bekerja di Jakarta sekitarnya. Populasi adalah semua yang memenuhi kriteria dimaksud dari penelitian ini, dan populasi dimaksud sulit untuk dihitung sehingga karena keterbatasan dana dan waktu maka populasi tidak akan dihitung. Sampel ditentukan dengan jumlah responden yang bersedia mengisi G-form yang disebarkan melalui media sosial dalam waktu 1 bulan. Dengan demikian teknik pengambilan sampel mengikuti teknik convenience sampling.

\section{Karakteristik Responden}

Karakteristik responden peneltian remote workers millennials yang dapat dikumpulkan dari penyebaran kuesioner di jakarta terdiri dari 100 sampel. Responden terdiri dari $62 \%$ wanita dan $38 \%$ pria. Data lain yaitu lama bekerja lebih dari 5 tahun $40 \%$ sisanya kurang dari 5 tahun $60 \%$. Responden $56 \%$ belum menikah dan belum memiliki anak $72 \%$, sedangkan penghasilan terbanyak di range Rp5.000.000-Rp10.000.000 sebanyak $51 \%$.

\section{Analisis Deskriptif}

Passion remote workers memiliki overall mean score yang berkategori tinggi karena berada dalam interval 3,43-4,23 yakni 3,57, hasil ini mengindikasikan umumnya remote workers millennials bekerja sesuai passion yang dimiliki. Dari analisis tersebut diketahui dimensi harmonious passion memiliki average mean score lebih tinggi dibandingkan obsessive passion $3,95>3,03$ dapat disimpulkan bahwa remote workers millennials umumnya memiliki pekerjaan yang sesuai dengan harmonious passion dalam dirinya. Variabel Task Characteristics Autonomy memiliki overall mean score 3,707 dimana berkategori tinggi karena berada di interval 3,43-4,23. Dimensi work scheduling autonomy merupakan dimensi yang memiliki nilai rerata tertinggi, yakni 3,776 .

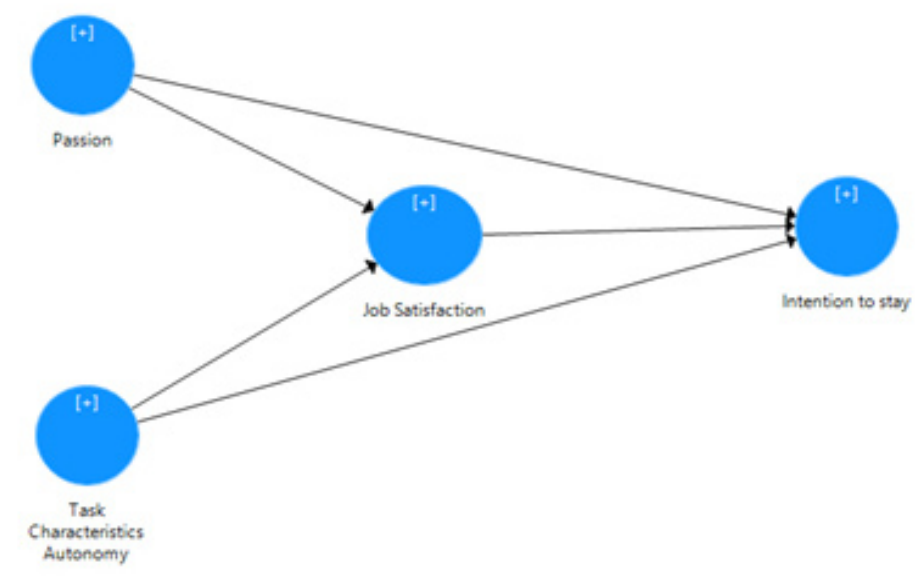

Gambar 1. Kerangka pemikiran penelitian 
Variabel job satisfaction memiliki overall mean score 3,585 berdasarkan skala interval yang ada variabel job satisfaction masuk dalam kategori tinggi 3,43-4,23. Dapat disimpulkan bahwa remote workers millennials job satisfaction yang tinggi, khususnya pada dimensi work itself satisfaction sebesar 3,72 diikuti dengan dimensi relation 3,62, job in general 3,568, reward 3,55 , growth 3,405. Variabel intention to stay memiliki overall mean score 3,434 berada dalam kategori interval tinggi 3,43-4,23. Nilai tersebut menggambarkan bahwa tingkat intention to stay remote workers millennials berada pada tingkat yang tinggi. Pada dimensi pikiran untuk bertahan memiliki average mean score 3.485, pikiran untuk mencari alternatif 3,41 , niat untuk bertahan 3,38. Tabel rata-rata dapat dilihat di Tabel 1 .

Tabel 1. Rata-rata dimensi variabel

\begin{tabular}{|c|c|}
\hline \multicolumn{2}{|l|}{ Overall Mean Score } \\
\hline \multicolumn{2}{|l|}{ Passion } \\
\hline Harmonious Passion Average Mean Score & 3,95 \\
\hline Obsessive Passion Average Mean Score & 3,0325 \\
\hline General Passion Average Mean Score & 3,8 \\
\hline Overall Mean Score Passion & 3,57 \\
\hline \multicolumn{2}{|l|}{ Task Characteristics Autonomy } \\
\hline $\begin{array}{l}\text { Work Scheduling Autonomy Average mean } \\
\text { score }\end{array}$ & 3,776 \\
\hline $\begin{array}{l}\text { Decision-Making Autonomy Average mean } \\
\text { score }\end{array}$ & 3,66 \\
\hline Work Method Autonomy Average mean score & 3,696 \\
\hline $\begin{array}{l}\text { Overall Mean Score Task Characteristics } \\
\text { Autonomy }\end{array}$ & 3,707 \\
\hline \multicolumn{2}{|l|}{ Job Satisfaction } \\
\hline Work itself Average mean score & 3,72 \\
\hline Reward Average mean score & 3,55 \\
\hline Relation Average mean score & 3,62 \\
\hline Job in general Average mean score & 3,568 \\
\hline Growth Average mean score & 3,405 \\
\hline Overall Mean Score Job Satisfaction & 3,585 \\
\hline \multicolumn{2}{|l|}{ Intention to Stay } \\
\hline Pikiran untuk bertahan Average mean score & 3,485 \\
\hline $\begin{array}{l}\text { Pikiran untuk mencari alternatif Average } \\
\text { mean score }\end{array}$ & 3,41 \\
\hline Niat untuk bertahan Average mean score & 3,38 \\
\hline Overall Mean Score Intention to Stay & 3,434 \\
\hline
\end{tabular}

\section{Uji dan Evaluasi Model SEM-PLS}

Pengujian dan evaluasi model menggunakan SEMPLS. Pada model penelitian ini terdapat dua variabel independen, satu variabel mediasi, dan satu variabel dependen yakni Passion yang terdiri dari 10 pernyataan Pas_1 - Pas_10, Task Characteristics Autonomy yang terdiri dari 14 pernyataan TCA_1 - TCA_14, Job Satisfaction yang terdiri dari 18 pernyataan TCA_1 TCA_18, dan yang terakhir intention to stay terdiri dari 5 pernyataan ITS_1 - ITS_5. Pengujian menggunakan dua tahap, yakni outer model dan inner model. Outer model terdiri dari uji Convergent Validity, Discriminant Validity, dan Composite Reliability dan Inner model terdiri dari uji Bootstrapping. Convergent validity mengukur nilai loading factor yang ditetapkan dalam model reflektif SEM-PLS yakni $>0,70$, penggunaan average variance extracted (AVE) sebagai kriteria pengujian convergent validity Cut-off value AVE yang sering digunakan adalah 0,50 sebagai convergent validity yang baik (Ghozali, 2014). Nilai diskriminan Validity dapat dilihat dari Cross Loading Factors seperti terlihat dalam Tabel 2.

Uji Reliabilitas dengan Cronbach Alpha minimal 0,7, Composite Reliability ini menunjukan internal consistency, nilai composite reliability yang tinggi menunjukan nilai konsistensi dari masing-masing indikator dalam mengukur konstruknya. Nilai CR diharapkan $>0,7$. Dari 47 item yang digunakan dalam kuesioner terdapat 10 item yang tidak valid karena outer loading $<0,7$, sehingga aka tersisa 37 item yang kemudian dapat lanjut ke tahap pengolahan validity berdasarkan nilai rata-rata varians yang di ekstrak (AVE).

Berdasarkan kriteria menghitung validitas diskriminan dengan AVE, seluruh variabel penelitian harus $>0,5$ maka sesuai pada Tabel 3 seluruh variabel dan item dalam penelitian ini sudah memenuhi kriteria validitas konstruk. Dari hasil Cross-Loading factor, seluruh item telah memenuhi syarat $>0,7$ dengan asumsi item TCA_11 mengalami pembulatan ke 0,7 sehingga seluruh variabel telah valid secara diskriminan. 
Tabel 2. Cross-Loading Factor

\begin{tabular}{|c|c|c|c|c|}
\hline & Intention to stay & Job Satisfaction & Passion & Task Characteristics Autonomy \\
\hline ITS_1 & $0,8714 *$ & 0,5909 & 0,5264 & 0,4134 \\
\hline ITS_2 & $0,9295^{*}$ & 0,5859 & 0,5476 & 0,4504 \\
\hline ITS_3 & $0,8443^{*}$ & 0,5387 & 0,5074 & 0,4034 \\
\hline ITS_5 & $0,8563^{*}$ & 0,5777 & 0,4976 & 0,4249 \\
\hline JS_1 & 0,5784 & $0,8489^{*}$ & 0,5139 & 0,5687 \\
\hline JS_2 & 0,5769 & $0,768^{*}$ & 0,5129 & 0,4829 \\
\hline JS_3 & 0,5157 & $0,7362 *$ & 0,4221 & 0,5486 \\
\hline JS_4 & 0,5654 & $0,7485^{*}$ & 0,4447 & 0,5122 \\
\hline JS_5 & 0,5574 & $0,7947^{*}$ & 0,5586 & 0,5626 \\
\hline JS_6 & 0,5407 & $0,7867^{*}$ & 0,445 & 0,5558 \\
\hline JS_7 & 0,5113 & $0,775^{*}$ & 0,4379 & 0,641 \\
\hline JS_8 & 0,3782 & $0,7265^{*}$ & 0,2704 & 0,6448 \\
\hline JS_9 & 0,6065 & $0,8231^{*}$ & 0,5941 & 0,5886 \\
\hline JS_10 & 0,5811 & $0,796^{*}$ & 0,5953 & 0,6138 \\
\hline JS_11 & 0,5232 & $0,7474 *$ & 0,4811 & 0,5856 \\
\hline JS_12 & 0,4899 & $0,8502^{*}$ & 0,5 & 0,6153 \\
\hline JS_13 & 0,4128 & $0,7396^{*}$ & 0,5147 & 0,6067 \\
\hline JS_14 & 0,5858 & $0,8938^{*}$ & 0,5205 & 0,6564 \\
\hline JS_15 & 0,4373 & $0,729^{*}$ & 0,4501 & 0,4913 \\
\hline JS_16 & 0,5347 & $0,8026^{*}$ & 0,4572 & 0,5418 \\
\hline JS_17 & 0,5044 & $0,8763^{*}$ & 0,5248 & 0,6846 \\
\hline JS_18 & 0,3191 & $0,7233^{*}$ & 0,4571 & 0,559 \\
\hline PAS_1 & 0,434 & 0,4615 & $0,7746^{*}$ & 0,3566 \\
\hline PAS_2 & 0,4681 & 0,3783 & $0,7646^{*}$ & 0,3353 \\
\hline PAS_4 & 0,4116 & 0,418 & $0,7681^{*}$ & 0,3747 \\
\hline PAS_5 & 0,361 & 0,4985 & $0,745^{*}$ & 0,4772 \\
\hline PAS_7 & 0,5086 & 0,5363 & $0,736^{*}$ & 0,4077 \\
\hline PAS_10 & 0,5085 & 0,5057 & $0,7842^{*}$ & 0,3412 \\
\hline TCA_1 & 0,2972 & 0,504 & 0,2628 & $0,7177^{*}$ \\
\hline TCA_2 & 0,3459 & 0,62 & 0,4051 & $0,8331^{*}$ \\
\hline TCA_3 & 0,3428 & 0,5487 & 0,4495 & $0,8161^{*}$ \\
\hline TCA_4 & 0,4033 & 0,6339 & 0,4117 & $0,876^{*}$ \\
\hline TCA_5 & 0,466 & 0,5807 & 0,439 & $0,8215^{*}$ \\
\hline TCA_6 & 0,475 & 0,6962 & 0,4239 & $0,9052^{*}$ \\
\hline TCA_7 & 0,4678 & 0,6567 & 0,5536 & $0,8359^{*}$ \\
\hline TCA_8 & 0,3992 & 0,6529 & 0,3922 & $0,8419^{*}$ \\
\hline TCA_11 & 0,312 & 0,4896 & 0,3069 & $0,6843^{*}$ \\
\hline
\end{tabular}

*confirmatory loading factor

Tabel 3. Validitas diskriminan

\begin{tabular}{lc}
\hline & Rata-rata Varians Diekstrak (AVE) \\
\hline Intention to Stay & 0,7674 \\
Job Satisfaction & 0,622 \\
Passion & 0,5811 \\
Task Characteristics Autonomy & 0,6681 \\
\hline
\end{tabular}


Seluruh variabel memenuhi kriteria Cronbach's Alpha > 0,7 dan skor Reliabilitas Komposit > 0,7 seperti terlihat di Tabel 4 dimana artinya masing-masing variabel sudah reliabel sehingga dapat dengan konsisten, dan tepat untuk digunakan sebagai variabel yang akan di bootstrapping pada Inner Model Evaluation.

Bootstrapping digunakan sebagai metode untuk menguji hipotesis dalam penelitian ini, dimana sub-sample seperti yang telah dijelaskan pada bab sebelumnya yakni berjumlah 5000 sub-sample guna mendapatkan hasil yang setara dengan level signifikansi 0,05 . Artinya, dari 100 sampel asli akan diuji secara berulang hingga mencapai 5000 kali dengan software SmartPLS 3,0 hasil bootstrap akan didapatkan T-statistic dan $P$ Values yang kemudian dibandingkan dengan nilai T-Tabel 1,660 jika T-Stat > T-Tabel maka H1 diterima, dengan jumlah sampel 100 dan tingkat signifikansi 0,05 diperoleh hasil bootstrapping seperti terlihat di Tabel 5.

Berdasarkan hasil bootstrapping yang telah dilakukan maka semua hipotesis diterima kecuali hipotesis 2 yakni Task characteristics autonomy berpengaruh signifikan terhadap Intention to stay. Dari tabel efek tidak langsung spesifik menyatakan bahwa variabel job satisfaction mampu memediasi secara penuh kedua variabel independen dapat dilihat di Tabel 6.

Hasil bootstrapping menyatakan $\mathrm{H} 1 \mathrm{t}$-stat $=3.254$ $>$ t-tabel 1.660 maka H1 diterima yakni passion berpengaruh signifikan terhadap intention to stay remote workers millennials, temuan ini didukung oleh penelitian sebelumnya, yaitu Houlfort et al. (2014) harmonious passion berpengaruh signifikan dalam menurunkan tingkat turn over intention, penelitian lain oleh Burke et al.(2014) menyatakan harmonious passion berpengaruh negatif signifikan terhadap intention to quit.

Hasil boostrapping menyatakan $\mathrm{H} 2$ t-stat $=0.3034<$ t-tabel 1,660. Oleh karena itu, H2 ditolak yakni task characteristics autonomy tidak berpengaruh signifikan terhadap intention to stay remote workers millennials, hal ini bertolak belakang dengan hasil penelitian sebelumnya yang dilakukan oleh Mustapha, et al.(2010) dimana ditemukan fakta job design dalam job autonomy berpengaruh positif signifikan terhadap intention to stay pekerja yang memiliki status single mother di Malaysia. Penelitian oleh Agarwal dan Gupta (2018) menyatakan bahwa job characteristics berpengaruh signifikan terhadap turnover intention para manajer. Maka terjadi research gap pada penelitian ini, hal ini mungkin terjadi akibat dari perbedaan objek penelitian, dimana kedua penelitian sebelumnya memiliki karakteristik responden yang berbeda dengan responden penelitian ini. Dalam penelitian ini responden merupakan $100 \%$ Millennials dan $100 \%$ Remote workers yang pada tugasnya memang memiliki tingkat otonomi yang tinggi dalam pekerjaan pokok sehari-hari, hal ini dapat memengaruhi keputusan untuk tetap tinggal diperusahaan. Remote workers mungkin menganggap tingkat otonomi yang tinggi dalam pekerjaan seharihari bukan lagi sesuatu yang spesial dan bukan faktor yang ditawarkan untuk membuat mereka bertahan dalam perusahaan ditempat mereka bekerja. Remote workers mungkin menganggap otonomi tinggi merupakan hal yang biasa dalam pekerjaannya seharihari berbeda dengan jenis pekerjaan konvensional yang tidak mengutamakan tingkat otonomi.

Tabel 4. Uji reliabilitas

\begin{tabular}{lcc}
\hline & Cronbach's Alpha & Reliabilitas Komposit \\
\hline Intention to Stay & 0,8984 & 0,9295 \\
Job Satisfaction & 0,9639 & 0,9672 \\
Passion & 0,8562 & 0,8927 \\
Task Characteristics Autonomy & 0,9369 & 0,9473 \\
\hline
\end{tabular}

Tabel 5. Hasil Bootstrapping

\begin{tabular}{lcc}
\hline Bootstrapping & T Statistik (O/STDEV) & P Values \\
\hline Job Satisfaction $\rightarrow$ Intention to Stay & 3,9407 & 0,0001 \\
Passion $\rightarrow$ Intention to Stay & 3,254 & 0,0011 \\
Passion $\rightarrow$ Job Satisfaction & 4,182 & 0,0000 \\
Task Characteristics Autonomy $\rightarrow$ Intention to Stay & 0,303 & 0,7616 \\
Task Characteristics Autonomy $\rightarrow$ Job Satisfaction & 6,520 & 0,0000 \\
\hline
\end{tabular}


Tabel 6. Hasil Bootstrapping tidak langsung spesifik

\begin{tabular}{lcc}
\hline Efek tidak langsung spesifik & T Statistik (O/STDEV) & P Values \\
\hline Passion $\rightarrow$ Job Satisfaction $\rightarrow$ Intention to Stay & 3,2073 & 0,0013 \\
Task Characteristics Autonomy $\rightarrow$ Job Satisfaction $\rightarrow$ Intention to Stay & 3,1434 & 0,0017 \\
\hline
\end{tabular}

$\mathrm{H} 3$ diterima yakni passion berpengaruh terhadap job satisfaction remote workers millennials $(\mathrm{H} 3 \mathrm{t}$-stat $=4,182$ $>$ t-tabel=1,660). Temuan ini sejalan dengan penelitian sebelumnya, yakni Pathak dan Srivastava, (2020) mengemukakan bahwa passion berpengaruh positif signifikan terhadap job satisfaction, Papadimitriou et al.(2017) menyatakan variabel passion berpengaruh positif dan signifikan terhadap tingkat job satisfaction.

H4 diterima ( $\mathrm{t}$-stat $=0,65203>\mathrm{t}$-tabel $=1,660$ ), yaitu task characteristics autonomy berpengaruh signifikan terhadap job satisfaction, temuan ini sejalan dengan temuan penelitian sebelumnya Abid et al.(2013) job design berpengaruh signifikan terhadap tingkat satisfaction pekerja. Hal ini membuktikan bahwa otonomi pekerjaan bagi kaum milenial menjadi faktor penentu kepuasan kerja. Sesuai dengan profil milenial yang disebutkan dalam riset sebelumnya yang mana millennials akan mencari pekerjaan yang penuh arti serta mendukung autonomy, kebebasan, dan memiliki kecenderungan untuk meninggalkan organisasi yang mendukung birokrasi manajemen tradisional (Armour, 2005; Becton et al. 2014)

H5 diterima ( $\mathrm{t}$-stat $=3,9407>\mathrm{t}$-tabel $=1,660)$ (TCAJS-ITS t-stat $=3,1434>\mathrm{t}$-tabel $=1,660$ ) (PAS-JS-ITS $\mathrm{t}$-stat $=3,2073>\mathrm{t}$-tabel $=1,660)$ job satisfaction mampu memediasi pengaruh passion dan task characteristics autonomy terhadap intention to stay, temuan ini didukung penelitian sebelumnya Purba dan Ananta (2018) menyatakan job satisfaction mampu memediasi pengaruh variabel passion terhadap turnover intention. Sesuai dengan penelitian Ferreira et al.(2017) yang menyatakan bahwa job satisfaction mampu memediasi pengaruh variabel task characteristics (signifikansi dan identitas) terhadap turnover intention. Dari temuan in, kepuasan kerja menjadi faktor yang sangat berperan dalam meningkatkan keinginan milenial untuk bertahan dimana kepuasan kerja tersebut dapat ditingkatkan dengan hadirnya passion dan otonomi dalam dunia kerja milenial agar kecenderungan kaum milenial untuk berpindah pindah pekerjaan tidak meningkat.

\section{Implikasi Manajerial}

Pada pembahasan sebelumnya diketahui bahwa variabel Job satisfaction mampu memediasi pengaruh passion dan task characteristics autonomy terhadap intention to stay remote workers millennials pada responden penelitian. Oleh karena itu, sebagai implikasi bagi perusahaan diperlukan untuk meningkatkan job satisfaction karyawan remote workers khususnya dari aspek Growth (average mean score 3,405) dalam upaya meningkatkan intention to stay remote workers millennials.

Dalam meningkatkan aspek growth bagi karyawan, perusahaan dapat mengadakan Employee development program. Dalam program ini dapat diberikan job enrichment, training kepemimpinan, hal-hal yang memberikan stimulus kepada seseorang untuk selalu berkembang di perusahaan tersebut. Employee development program tentu harus dibarengi dengan pemberian reward yang sepadan dengan perkembangan seorang karyawan dalam perusahaan. Jika perusahaan mengakomodasi tingkat growth karyawannya serta memberikan reward yang sesuai, maka tingkat kepuasan karyawan akan meningkat. Hal ini menjadi sangat penting karena hasil penelitian menunjukkan kepuasan kerja menjadi variabel mediasi yang sangat menentukan niat milenial untuk bertahan dalam organisasi. Agar kepuasan kerja meningkat organisasi dapat mendesain pekerjaan yang dalam penelitian terbukti memiliki efek posistif dan signifikan meningkatkan kepuasan kerja. Oleh sebab itu, pihak perusahaan dapat lebih fokus dalam merancang pekerjaan secara komprehensif.

Job design remote workers sebaiknya dibuat sedemikian rupa agar mampu mengakomodasi passion remote workers, dan tidak semata hanya memberikan tingkat otonomi yang tinggi dalam tiap pekerjaannya namun harus membuat karyawan merasa bermakna dengan melakukan pekerjaan tersebut bagi dirinya di dalam perusahaan, membuat karyawan merasa terus berkembang ketika melakukan pekerjaan tersebut, serta memastikan karyawan selalu mendapatkan feedback 
yang membangun dari atasan dan rekan kerja. Dalam pemberian kesempatan otonomi kepada karyawan sebaiknya perusahaan memberikan kesempatan yang lebih terhadap aspek decision making karyawan remote workers (average mean score 3,66).

Diketahui hasil uji bootstrapping menyatakan bahwa task characteristics autonomy tidak memiliki pengaruh signifikan terhadap intention to stay secara langsung. Hal ini mungkin terjadi akibat tingkat otonomi bukan lagi suatu hal yang spesial dalam jenis pekerjaan remote working melainkan sebuah keharusan yang dimiliki oleh setiap remote workers. Dengan kata lain milenials yang bekerja dengan sistem remote worker sudah yakin bahwa otonomi dalam bekerja menjadi bagian dari desain pekerjaannya dan itu bukan menjadi pertimbangan untuk stay dalam satu perusahaan, namum otonomi itu menjadi pendongkrak kepuasan kerja yang menentukan tingkat intention to stay. Hal ini didukung hasil uji task characteristics autonomy merupakan variabel yang paling kuat pengaruhnya terhadap tingkat job satisfaction. Oleh karena itu, tingkat otonomi harus terus disesuaikan denganperubahan lingkungan kerja dan bisnis yang selalu dinamis menghadapi industri 4,0 dan industri berikutnya. .

Dari pembahasan sebelumnya, variabel Passion pada remote workers generasi milenial berada pada kategori tinggi hal ini berarti remote workers millennials umumnya bekerja sesuai dengan passionnya khususnya harmoniouspassion. TaskCharacteristic Autonomypada remote workers generasi milenial pada kategori tinggi dimana remote workers menginginkan pekerjaan yang dapat memberikan otonomi tinggi dalam pengambilan keputusan. Perusahaan dapat meningkatkan kepuasan kerja bila dalam rekrutmen meyakinkan calon pekerja memiliki passion pada pekerjaan yang dipiih.

Job satisfaction pada remote workers generasi milenial berada pada kategori tinggi dimana remote workers millenials tidak hanya menginginkan reward dan relasi saja melainkan menginginkan kemungkinan untuk berkembang didalam organisasi tersebut. Hal ini tentu dapat dijadikan pertimbangan dalam upaya peningkatan intention to stay remote workers dengan memperhatikan pengembangan karir dalam organisasi. Khususnya dalam variabel job satisfaction yang mampu memediasi secara penuh pengaruh passion dan task characteristics autonomy terhadap intention to stay

\section{KESIMPULAN DAN SARAN}

\section{Kesimpulan}

Hasil penelitian membuktikan bahwa kaum milenial dapat ditingkatkan kepuasan kerjanya melalui passion dan otonomi tugas yang dirasakan pada pekerjaannya. Kepuasan kerja dibuktikan dapat meningkatkan keinginan untuk bertahan secara signifikan dan memediasi pengaruh passion dan otonomi tugas dalam meningkatkan niat untuk bertahan kaum milenial. Di sisi lain passion secara langsung dapat berpengaruh pada niat untuk bertahan. Dengan demikian milenial yang mempunyai passion pada pekerjaannya diharapkan akan lebih puas dan dapat tinggal pada organisasi dalam jangka panjang.

\section{Saran}

Dari kesimpulan tersebut, peneliti menyarankan bagi perusahaan dengan pekerja remote sudah waktunya terus memperhatikan proses rekrutmen karyawan dengan passion yang baik di bidangnya. Selanjutnya, perusahaan mendesain pekerjaan yang dapat mengakomodasi passion dari karyawan itu tidak semata mata mengandalkan tingkat otonomi saja. Pihak perusahaan dapat lebih fokus dalam merancang pekerjaan secara komprehensif. Di samping itu, perusahaan juga disarankan untuk memperhatikan tingkat job satisfaction karyawan remote workers millennials. Cara meningkatkan job satisfaction salah satunya dengan membuat program employee development hal ini akan meningkatkan aspek growth dari job satisfaction, kemudian diikuti dengan memberikan reward yang sesuai, reward dapat berbentuk material dan non material. Dengan meningkatnya job satisfaction akan diikuti dengan meningkatnya intention to stay karyawan.

Variable task characteristics autonomy sebagai variabel independen dapat dikembangkan dengan variabel lain seperti career satisfaction untuk melihat dampaknya secara lebih luas pada milenials. Selanjutnya disarankan menggunakan jumlah sampel yang lebih besar agar mampu mengestimasi populasi dengan lebih baik, sampel dapat diambil dengan 10 kali dari jumlah indikator penelitian.

Penelitian ini tentu memiliki keterbatasan, yang mana sampel tidak dapat mewakili populasi karena jumlah populasi sulit untuk dihitung. Di samping itu sampel 
juga kurang memadai dan tidak dapat diambil secara random. Dengan demikian hasil penelitian ini tidak bisa digeneralisir dan hanya dapat memprediksi gambaran topik penelitian pada millenials yang diteliti.

\section{DAFTAR PUSTAKA}

Abid AM, Sarwar A, Imran K, Jabbar A, Hannan A. 2013. Effect of job design on employee satisfaction (a study of fertilizer companies listed in Lahore Stock Exchange). European Journal of Business and Management 5(19):1-7. https:// doi.org/10.1108/PR-09-2016-0229

Agarwal UA, Gupta V. 2018. Relationships between job characteristics, work engagement, conscientiousness and managers' turnover intentions: A moderated-mediation analysis. Personnel Review 47(2):353-377.

Armour S. 2005. Generation Y: they've arrived at work with a new attitude. https://www.usatoday.com. [7 November 2020].

Becton J, Walker H, Jones-Farmer A. 2014. Generational differences in workplace behavior. Journal of Applied Social Psychology 44(3):175-189. https://doi.org/10.1111/jasp.12208

Burke RJ, Astakhova MN, Hang H. 2014. Work passion through the lens of culture: harmonious work passion, obsessive work passion, and work outcomes in Russia and China. Journal of Business and Psychology 30(3):457-471. https:// doi.org/10.1007/s10869-014-9375-4

Cho S, Lee J, Mark B, Yun S. 2012. Turnover of new graduate nurses in their first job using survival analysis. Journal of Nursing Scholarship 44(1):63-70. https://doi.org/10.1111/j.15475069.2011.01428.x

DelCampo RG., Haggerty LA, Haney MJ, Knippel LA. 2011. Managing the multi-generational workforce: From the GI generation to the millennials. Human Resource Management International Digest 20(2). https://doi. org/10.1108/hrmid.2012.04420baa.017

Ferreira AI, Martinez LF, Lamelas JP, Rodrigues RI. 2017. Mediation of job embeddedness and satisfaction in the relationship between task characteristicsandturnover.InternationalJournal of Contemporary Hospitality Management 29(1):248-267.https://doi.org/10.1108/IJCHM03-2015-0126
Frian A, Mulyani F. 2018. Millenials employee turnover intention in Indonesia. Innovative Issues and Approaches in Social Sciences 11(3):90-128.

Ghozali I. 2014. Structural Equation Modeling Metode Alternatif dengan Partial Least Squares (PLS). Semarang: Badan Penerbit Universitas Diponegoro.

Houlfort N, Philippe FL, Vallerand RJ, Me'nard J. 2014. On passion and heavy work investment: personal and organizational outcomes. Journal of Managerial Psychology 29(1):25-45.

Mobley WH, Horner SO, Hollingsworth AT. 1978. An evaluation of precursors of hospital employee turnover. Journal of Applied Psychology 63:408414.

Morgeson FP, Humphrey SE. 2006. The Work Design Questionnaire (WDQ): Developing and validating a comprehensive measure for assessing job design and the nature of work. Journal of Applied Psychology 91(6):1321-1339.

Mustapha N, Ahmad A, Uli J, Idris K. 2010. Job characteristics as antecedent of intention to stay and mediating effects of work family facilitation and family satisfaction among single mothers in Malaysia. International Journal of Business and Social Science 1(3):59-74. https://doi. org/10.1037/0021-9010.91.6.1321

Oktariani D, Hubeis AV, Sukandar D. 2017. Kepuasan kerja generasi $\mathrm{x}$ dan generasi $\mathrm{y}$ terhadap komitmen kerja di Bank Mandiri Palembang. Jurnal Aplikasi Bisnis dan Manajemen 3(1).

Olorunfemi AO. 2013. Telecommuting to improve quality of worklife of women workers in lagos state tertiary institutions. Journal of Studies in Education3(2):222-233.https://doi.org/10.5296/ jse.v3i2.3410

Purba SD, Ananta AN. 2018. The effects of works passion, work engagement and job satisfaction on turn over intention of the millennial generation. Jurnal Manajemen dan Pemasaran Jasa 11(2):263-274.https://doi.org/10.25105/ jmpj.v11i2.2954

Spector P. 1997. Job Satisfaction: Application, Assessment, Cause, and Consequences. London: Sage Publications.

Vallerand R, Blanchard C, Mageau G, Koestner R, Ratelle C, Léonard M, Marsolais J. 2003. Les passions de l'âme: On obsessive and harmonious passion. Journal of Personality and Social Psychology 85(4):756-67. https://doi. org/10.1037/0022-3514.85.4.756 